\title{
Operational Problem Identified
}

National Cancer Institute

\section{Source}

National Cancer Institute. Operational Problem Identified. NCI Thesaurus. Code C92088.

Problems that occur during the performance, use, or functioning of the device. 